\title{
In Situ Synthesis and Characterization of ZnO/Chitosan Nanocomposite as an Adsorbent for Removal of Congo Red from Aqueous Solution
}

\author{
Nhu Thanh Nguyen, ${ }^{1}$ Ngoc Thinh Nguyen $\mathbb{D}^{1},{ }^{1}$ and Van Anh Nguyen $\mathbb{D}^{2}$ \\ ${ }^{1}$ School of Chemical Engineering, Hanoi University of Science and Technology, Hanoi 100000, Vietnam \\ ${ }^{2}$ Faculty of Natural Sciences and Technology, Hanoi Metropolitan University, Hanoi 100000, Vietnam \\ Correspondence should be addressed to Ngoc Thinh Nguyen; thinh.nguyenngoc@hust.edu.vn
}

Received 13 September 2019; Revised 19 November 2019; Accepted 30 November 2019; Published 17 January 2020

Guest Editor: Yongwei Chen

Copyright ( $) 2020$ Nhu Thanh Nguyen et al. This is an open access article distributed under the Creative Commons Attribution License, which permits unrestricted use, distribution, and reproduction in any medium, provided the original work is properly cited.

$\mathrm{ZnO} /$ chitosan nanocomposite was successfully synthesized by in-situ precipitation method. The material was characterized by XRD, FESEM, TEM, FTIR, BET, and TGA. Results show that $\mathrm{ZnO} /$ chitosan nanocomposite has spherical shape with the average size of 20-25 nm. BET surface area and the average pore size of $\mathrm{ZnO} /$ chitosan nanocomposite are $2.2436\left(\mathrm{~m}^{2} / \mathrm{g}\right)$ and $12.2 \mathrm{~nm}$, respectively. The material was applied as an adsorbent for congo red removal from aqueous solutions. The congo red adsorption is better described by the Langmuir model $\left(R^{2}=0.996\right)$ than by the Freundlich model $\left(R^{2}=0.962\right)$. Therefore, it can be presumed that congo red was adsorbed in a single monolayer with the theoretical maximum adsorption capacity of $227.3(\mathrm{mg} / \mathrm{g})$. This is comparable to other available adsorbents. It can be suggested that $\mathrm{ZnO}$ /chitosan nanocomposite could serve as promising adsorbent for congo red in wastewater treatment technology.

\section{Introduction}

Despite of the fact that water resource is critical for the survival of living organisms, it is facing unprecedented challenges. Water pollution has become one of the most serious global issues. One of the leading sources of water pollutions is without doubt industrial activities. Every day, huge amounts of industrial wastewater are discharged into water body, and this severely affects not only the health of all living forms but also the quality of the whole ecosystem. Particularly, wastewaters from textile, pharmaceutical, food, cosmetics, plastics, photographic, paper industries, etc. are releasing large quantities of organic dyes into the environment. It was estimated that the world production of dyes in 1990s was 1,000,000 tons. For decades, it has rapidly increased with more than 100,000 types of commercial dyes. Approximately, the amount of $8-20 \%$ of the used dyes entered water environment. Numbers of them are toxic or are carcinogenic substances that are resistant to environmental degradation [1-3]. This results in the essential needs of effective and eco-friendly methods to remove these toxic chemicals from water.
Congo red dye, a benzidine-based anionic bisazo dye [1-napthalenesulfonic acid, 3,3-(4,4-biphenylene bis (azo) bis (4-amino-) disodium salt, is an interest subject to researchers due to its high toxicity to humans and its stability in the environment. In addition, after entering human bodies congo red can be metabolized into benzidine, a well-known carcinogen and mutagen in human $[3,4]$.

Several methods have been proposed in order to remove organic dyes from aqueous solutions such as adsorption, chemical coagulation, biodegradation, and advanced oxidation processes [5-8]. Compared to others, adsorption is considered as one the most popular methods with the advantages of being simple and cost-effective $[9,10]$. Variety of materials have been investigated to be used as adsorbents for congo red, such as carbon-based materials, silica composites, cellulosic materials, and chitosan related materials [11-14]. Among them, chitosan would be a suitable candidate for producing the desirable adsorbents for congo red. Chitosan is an abundant biopolymer in nature. Its application as an adsorbent of heavy metal ions or colorants derives from its functional groups such as $\left(-\mathrm{NH}_{2}\right),(-\mathrm{OH})$. Nonetheless, chitosan has 
several limitations such as poor adsorption capacity, low mechanical strength, low water solubility, and ease of decomposition under acidic conditions [15]. For this reason, chitosan is usually combined with other substances such as hydroxyapatite, $\mathrm{TiO}_{2}, \mathrm{ZnO}, \mathrm{Fe}_{3} \mathrm{O}_{4}$ to form composites in order to overcome these disadvantages $[15,16]$. In this study, the aim was to synthesize $\mathrm{ZnO} /$ chitosan nanocomposite in situ from $\mathrm{Zn}^{2+}$ by a simple and cost-effective precipitation method that allows to prepare the material in a large-scale. The material was thoroughly characterized and applied to remove congo red in aqueous solutions.

\section{Materials and Methods}

2.1. Materials and Method. Chitosan flakes (molecular weight $\mathrm{Mw}=32 \mathrm{kDa}$ and degree of deacetylation $\mathrm{DD}=85 \%$ ) were prepared and characterized in our laboratory [17]. All other chemicals including $\mathrm{Zn}\left(\mathrm{NO}_{3}\right)_{2} \cdot 6 \mathrm{H}_{2} \mathrm{O}, \mathrm{CH}_{3} \mathrm{COOH}$, and $\mathrm{NaOH}$ were of analytical grade and used without further purification.

Chitosan solutions were prepared by completely dissolving $0.5 \mathrm{~g}$ of chitosan flakes in $100 \mathrm{~mL}$ of $\mathrm{CH}_{3} \mathrm{COOH} 1 \%$ solution. $\mathrm{ZnO} /$ chitosan nanocomposite was produced by in situ precipitation method. The weight ratio of $m_{\text {chitosan }} / m_{\mathrm{ZnO}}$ reported in former publications varies in a wide range from 0.084 to 1.0 [18-20]. In this study, the weight ratio of about 0.3 was selected. The amount of $6.246 \mathrm{~g}$ of $\mathrm{Zn}\left(\mathrm{NO}_{3}\right)_{2} \cdot 6 \mathrm{H}_{2} \mathrm{O}$ was added to $100 \mathrm{~mL}$ of chitosan solution. The mixture was stirred at $80^{\circ} \mathrm{C}$ for $30 \mathrm{~min}$. The $\mathrm{pH}$ of the obtained solution was adjusted to 10 using sodium hydroxide solution $0.1 \mathrm{M}$. The mixture was additionally stirred for 2 hours at $80^{\circ} \mathrm{C}$. The white precipitate was collected by centrifugation (Hettich Mikro 22R Centrifuges), washed with distilled water, and dried at $60^{\circ} \mathrm{C}$ overnight (8 hours). $\mathrm{ZnO}$ nanoparticles was synthesized by using similar procedure. However, $\mathrm{Zn}\left(\mathrm{NO}_{3}\right)_{2} \cdot 6 \mathrm{H}_{2} \mathrm{O}$ was mixed in $100 \mathrm{~mL}$ of distilled water instead of chitosan solution.

2.2. Characterization Methods. The synthesized $\mathrm{ZnO} /$ chitosan nanocomposite was characterized by X-ray diffraction (XRD, Bruker D8 advanced X-ray diffractometer) with $\mathrm{Cu}$ Ka radiation $(\lambda=1.54 \AA)$ and the scan rate of $0.02 \mathrm{~s}^{-1}$ from $20^{\circ}$ to $70^{\circ}$. Morphology of $\mathrm{ZnO} /$ chitosan nanocomposite was analyzed by Field Emission Hitachi S-4800 Scanning Electron Microscope (FE-SEM) and a transmission electron microscope (TEM), JEOL JEM-1010. Fourier transform infrared spectra (FT-IR) were obtained on a Nicolet iS10 Thermo Scientific spectrometer (USA). The thermal properties were studied by TGA (DSC131, Labsys TG/DSC1600, TMA, and Setaram, France). The nitrogen adsorption-desorption isotherms of the adsorbents (i.e. chitosan, $\mathrm{ZnO}$ nanoparticles and $\mathrm{ZnO} /$ chitosan nanocomposite) were recorded by the TriStar II 3020 nitrogen adsorption apparatus (Micromeritics Instruments, USA) at $77 \mathrm{~K}$. The pore size distribution and the BET specific surface area $\left(\mathrm{S}_{\mathrm{BET}}\right)$ of the samples were determined by the Barrett-Joyner-Halenda (BJH) method.

2.3. Adsorption Experiments. Chitosan used in adsorption experiment was prepared as the following: chitosan flakes were completely dissolved in $\mathrm{CH}_{3} \mathrm{COOH} 1 \%$ solution and then re- precipitated by increasing the $\mathrm{pH}$ of the solution using $\mathrm{NaOH}$ $0.1 \mathrm{M}$. The mixture was stirred for $60 \mathrm{~min}$. The precipitate was collected by centrifugation, washed with distilled water, and dried at $60^{\circ} \mathrm{C}$ overnight (8 hours).

The stock solution of congo red was prepared by disolving $1 \mathrm{~g}$ congo red in $1000 \mathrm{~mL}$ distilled water. Desired congo red solutions were obtained by diluting the stock solution $(1000 \mathrm{mg} / \mathrm{L})$. Congo red concentrations of the solutions were confirmed by Agilent $8453 \mathrm{UV}$ Vis-spectrophotometer at $497 \mathrm{~nm}$ before every adsorption experiment.

Batch experiments were carried out by mixing $0.02 \mathrm{~g}$ of the adsorbents with $40 \mathrm{~mL}$ of congo red solutions in $50 \mathrm{~mL}$-centrifuge tubes. The mixtures were ultrasonicated at $30^{\circ} \mathrm{C}$ (Elmasonic S100H Ultrasonic Bath) and then centrifuged at $6000 \mathrm{rpm}$. Congo red concentrations of supernatants were measured.

In order to find the equilibrium time of the congo red adsorption by $\mathrm{ZnO} /$ chitosan nanocomposite, the initial congo red concentration of $100 \mathrm{mg} / \mathrm{L}$ was applied. The supernatant was sampled at definite time intervals and measured for congo red concentration until negligible change in the congo red concentration was observed, signalling the equilibrium of the adsorption process. During the experiment, samples of supernatant were returned to the centrifuge tube after every measurement [21].

A series of solutions with different congo red concentrations varying from 100 to $550 \mathrm{mg} / \mathrm{L}$ was employed to determine the maximum congo red adsorption capacity of $\mathrm{ZnO} /$ chitosan nanocomposite. The reaction time was the equilibrium time of the congo red adsorption by $\mathrm{ZnO} /$ chitosan nanocomposite found in the previous experiment.

The congo red removal efficiencies of the three adsorbents were also compared by carrying out adsorption experiments with the initial congo red concentration of $100 \mathrm{mg} / \mathrm{L}$.

The adsorbed amount of congo red per unit of weight of adsorbent, $q_{t}(\mathrm{mg} / \mathrm{L})$, was calculated from the mass balance equation:

$$
q_{t}=\frac{\left(C_{0}-C_{t}\right)}{m},
$$

and percent of congo red removal:

$$
R \%=\frac{\left(C_{0}-C_{e}\right)}{C_{0}} \times 100,
$$

where $C_{0}, C_{t}$ and $C_{e}(\mathrm{mg} / \mathrm{L})$ are initial congo red concentration, the congo red concentration after time $t$, and the congo red concentration at equilibrium, respectively; $V(\mathrm{~L})$ is the volume of the solutions; and $m(\mathrm{~g})$ is the mass of the adsorbents.

\section{Results and Discussion}

3.1. Characterization of $\mathrm{ZnO} /$ Chitosan Nanocomposite. XRD patterns of $\mathrm{ZnO} /$ chitosan nanocomposite are shown in Figure 1 . The major peaks at scattering angles $(2 \theta)$ of $31.8^{\circ}, 34.4^{\circ}$, $36.2^{\circ}, 47.5^{\circ}, 56.6^{\circ}, 62.8^{\circ}, 66.3^{\circ}, 68.1^{\circ}$, and $69.3^{\circ}$ correspond to the lattice planes of (100), (002), (101), (102), (110), (103), (200), 


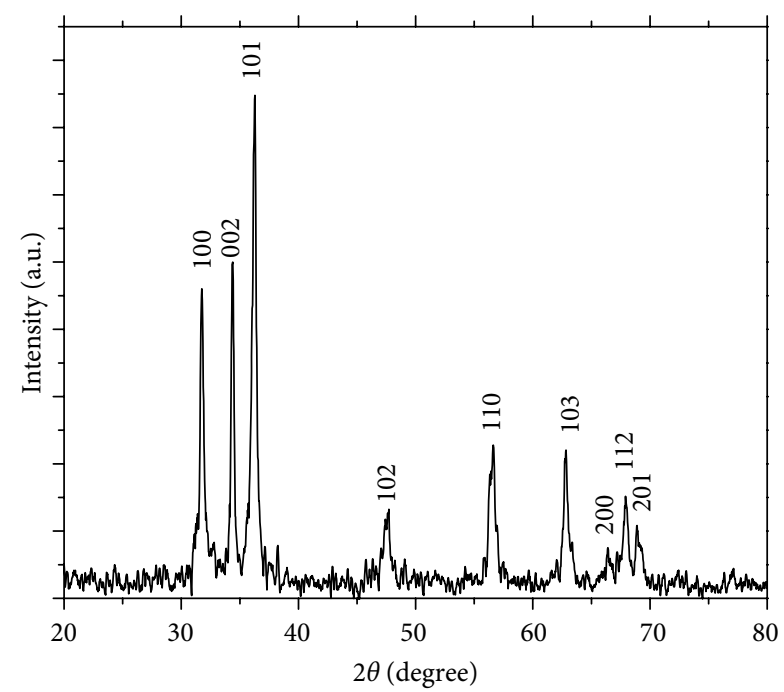

FIGURE 1: XRD patterns of $\mathrm{ZnO} /$ chitosan nanocomposite.

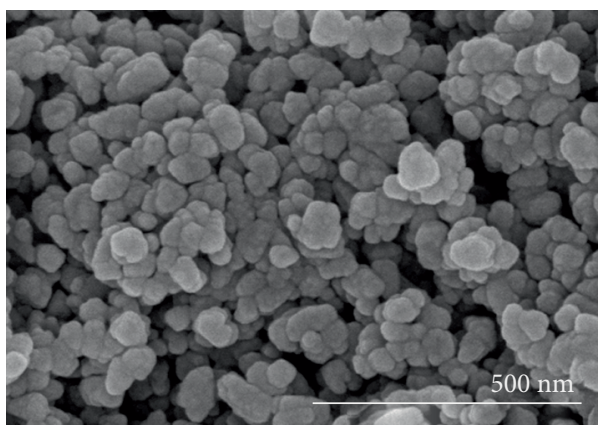

(a)

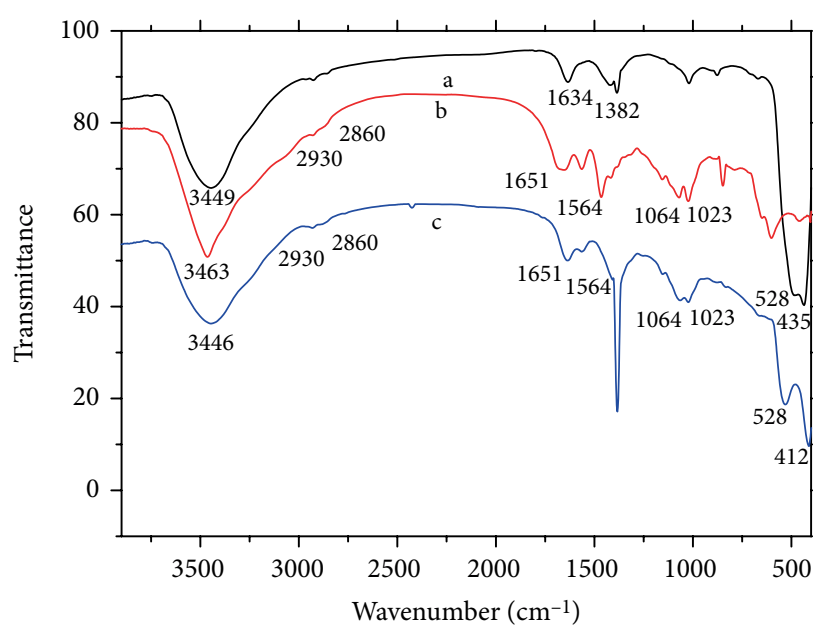

FIgURE 3: The FTIR spectra of ZnO nanoparticles (a), chitosan (b), and $\mathrm{ZnO} /$ chitosan nanocomposite (c).

FIGURE 2: FE-SEM image (a) and TEM image (b) of the $\mathrm{ZnO} /$ chitosan nanocomposite.

(112), and (201), respectively. These represent the wurtzite hexagonal phase of $\mathrm{ZnO}$, confirming the formation of $\mathrm{ZnO}$ particles. The observed diffraction reflections are well-matched with the reported literature as well as standard JCPDS data card No. 36-1451 [18, 19, 22, 23]. Other diffraction peaks referring to any impurities were not detected, suggesting that precipitated $\mathrm{Zn}(\mathrm{OH})_{2}$ was completely decomposed to $\mathrm{ZnO}$.

The crystal size of $\mathrm{ZnO} /$ chitosan nanocomposite was calculated from the broadening of diffraction peaks using DebyeScherer formula [5]:

$$
D=\frac{k \lambda}{\beta \cos \theta},
$$

where $D$ is crystal size, $k$ is constant (0.94), $\lambda=0.154 \mathrm{~nm}$ represents the wavelength of $\mathrm{X}$-ray radiation, $\beta$ is the full width at half maximum of diffraction peaks (FWHM) in radian, and $\theta$ is the Bragg's angle. The crystal size of the $\mathrm{ZnO} /$ chitosan nanocomposite was evaluated by measuring the FWHM of the most intense peak (101) because it has a relatively strong intensity and does not overlap with other diffraction peaks. Approximately, the average crystal size of $\mathrm{ZnO} /$ chitosan nanocomposite is of $22 \mathrm{~nm}$.

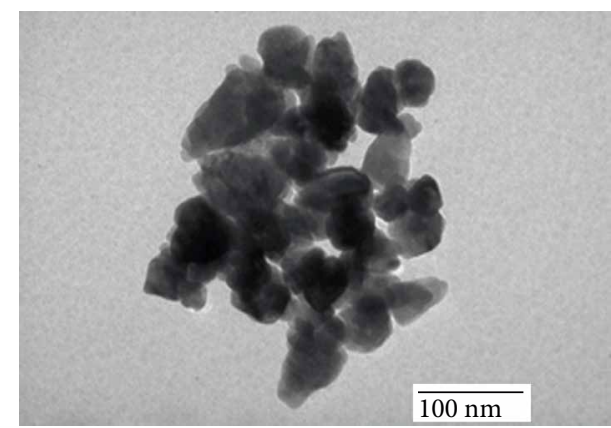

(b)
Figure 2 shows the FE-SEM (a) and TEM (b) images of the $\mathrm{ZnO} /$ chitosan nanocomposite. As can be seen, the spherical particles appear to be quite distinct and uniform, and the size of the particles ranges from 20 to $25 \mathrm{~nm}$.

Figure 3 shows the FTIR spectra of $\mathrm{ZnO}$ nanoparticles, chitosan, and $\mathrm{ZnO} /$ chitosan nanocomposite. In the FTIR spectrum of $\mathrm{ZnO}$ nanoparticles (Figure 3(a)), the peak at $3449 \mathrm{~cm}^{-1}$ corresponds to the $\mathrm{O}-\mathrm{H}$ stretching vibration of $\mathrm{H}_{2} \mathrm{O}$ in $\mathrm{ZnO}$; the peak at $1634 \mathrm{~cm}^{-1}$ may be due to the $\mathrm{O}-\mathrm{H}$ bending vibration; the $\mathrm{H}-\mathrm{O}-\mathrm{H}$ bending vibration or the absorbed $\mathrm{CO}_{2}$ bands may be responsible for the peak at $1382 \mathrm{~cm}^{-1}$. and the band in the range of $528-435 \mathrm{~cm}^{-1}$ refers to the stretching mode of $\mathrm{Zn}-\mathrm{O}$ [24-26]. In the spectrum of chitosan (Figure $3(\mathrm{~b})$ ), the broad peak at $3463 \mathrm{~cm}^{-1}$ is due to the $-\mathrm{OH} /-\mathrm{NH}_{2}$ stretching vibration; the peaks at 2930 and $2860 \mathrm{~cm}^{-1}$ are attributed to the $\mathrm{C}-\mathrm{H}$ stretching vibration; the peak at $1651 \mathrm{~cm}^{-1}$ corresponds to the amino group bending vibrations; the peak at $1564 \mathrm{~cm}^{-1}$ may be due to the deformation of amide II; and the peaks at 1064 and $1023 \mathrm{~cm}^{-1}$ may refer to the $\mathrm{C}-\mathrm{O}$ stretching vibration [27-31]. Compared to the spectrum of chitosan, a new band from 528 to $412 \mathrm{~cm}^{-1}$ referring to the $\mathrm{Zn}-\mathrm{O}$ stretching appears in the spectrum of $\mathrm{ZnO} /$ chitosan 


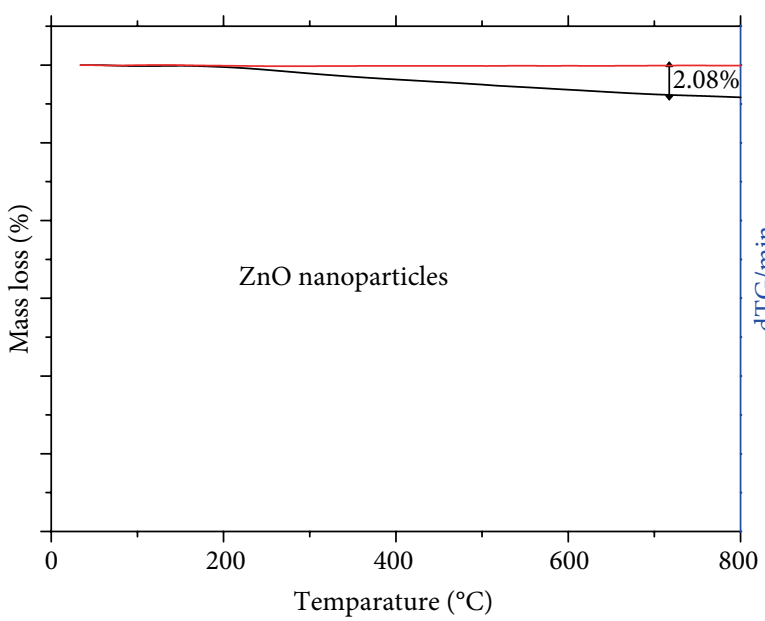

(a)

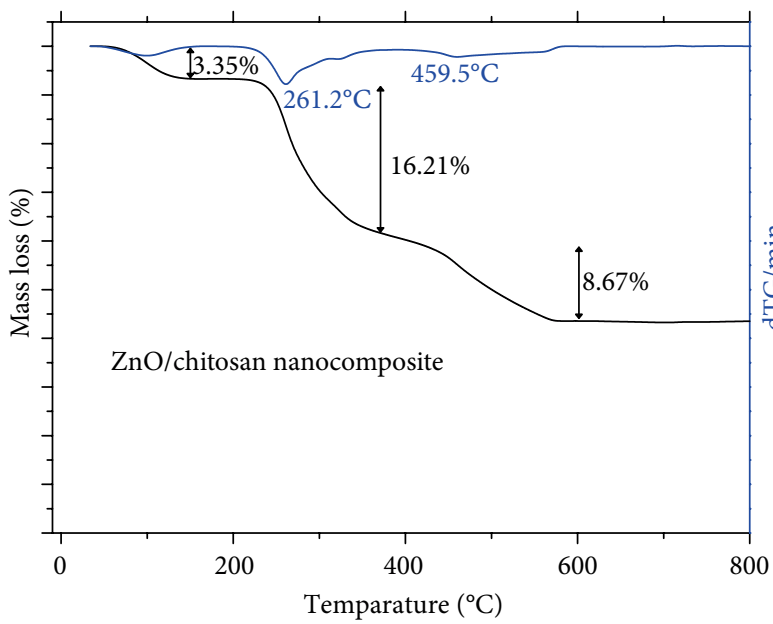

(c)

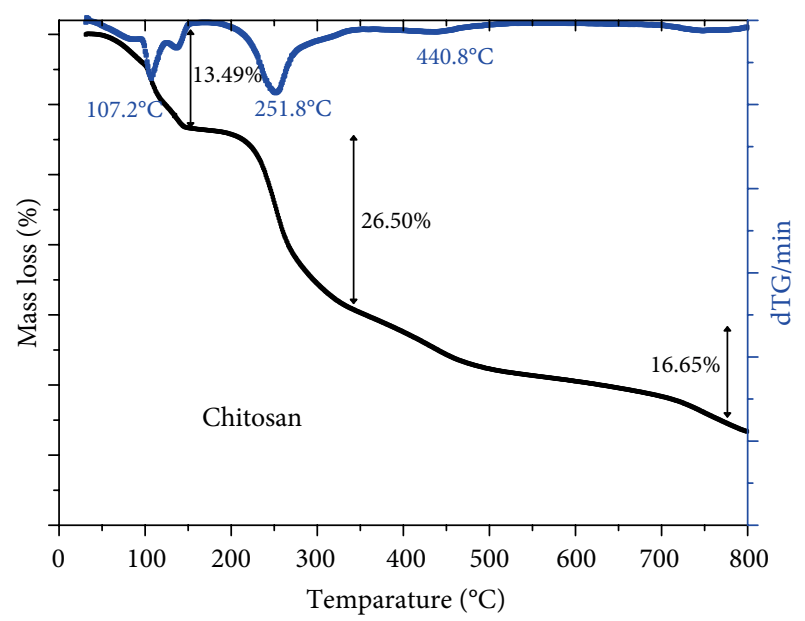

(b)

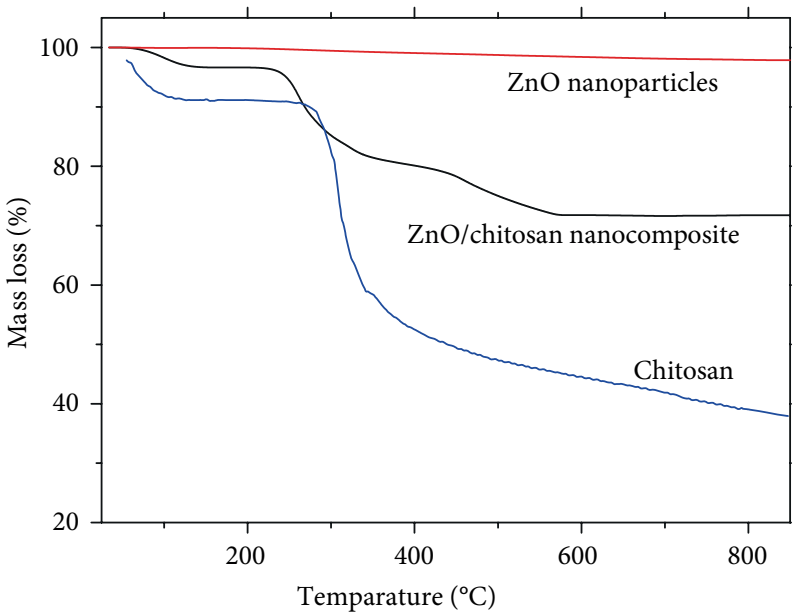

(d)

FIgURE 4: Thermo-gravimetric curves of $\mathrm{ZnO}$ nanoparticles (a), chitosan (b), and $\mathrm{ZnO} /$ chitosan nanocomposite (c).

TABLE 1: BET surface areas, pore volume, and pore size in the $\mathrm{ZnO}$ nanoparticles, chitosan and $\mathrm{ZnO} /$ chitosan nanocomposite.

\begin{tabular}{lccc}
\hline Sample & $\mathrm{S}_{\mathrm{BET}}\left(\mathrm{m}^{2} / \mathrm{g}\right)^{\mathrm{a}}$ & $\begin{array}{c}\text { Pore volume } \\
\left(\mathrm{cm}^{3} / \mathrm{g}\right)^{\mathrm{b}}\end{array}$ & $\begin{array}{c}\text { Average pore } \\
\text { size }(\mathrm{nm})^{\mathrm{c}}\end{array}$ \\
\hline $\begin{array}{l}\mathrm{ZnO} \\
\text { nanoparticles }\end{array}$ & 9.7852 & 0.031169 & 11.3386 \\
$\begin{array}{l}\text { Chitosan } \\
\begin{array}{l}\mathrm{ZnO} / \text { chitosan } \\
\text { nanocomposite }\end{array}\end{array}$ & 1.7461 & 0.010181 & 21.6846 \\
\hline
\end{tabular}

${ }^{a}$ BET surface area calculated from the linear part of the BET plot. ${ }^{b} \mathrm{BJH}$ adsorption cumulative volume of pores between $17.0 \AA$ and $3000.0 \AA$ diameter. ${ }^{c}$ Adsorption average pore diameter ( $4 \mathrm{~V} / \mathrm{A}$ by BET).

nanocomposite (Figure 3(c)). This indicates the existence of $\mathrm{ZnO}$ in the structure of the nanocomposite. In addition, the peak relating to the $-\mathrm{OH} /-\mathrm{NH}_{2}$ stretching vibration in chitosan $\left(\right.$ at $\left.3463 \mathrm{~cm}^{-1}\right)$ is broader and shifted to the lower wavenumber $\left(3446 \mathrm{~cm}^{-1}\right)$ in the nanocomposite, suggesting the
TABle 2: Parameters of the Langmuir and Freundlich adsorption isotherms.

\begin{tabular}{lcccccc}
\hline $\begin{array}{l}\text { Tem- } \\
\text { perature } \\
(\mathrm{K})\end{array}$ & $\begin{array}{c}q_{m} \\
(\mathrm{mg} / \mathrm{g})\end{array}$ & $\begin{array}{c}K_{L}(\mathrm{~L} / \\
\mathrm{mg})\end{array}$ & $R^{2}$ & $\begin{array}{c}K_{F} \\
(\mathrm{mg} / \mathrm{g}) \\
(\mathrm{L} / \mathrm{mg})^{1 / \mathrm{n}}\end{array}$ & $n$ & $R^{2}$ \\
\hline 303 & 227.3 & 0.048 & 0.996 & 101.3 & 7.91 & 0.962 \\
\hline
\end{tabular}

strong intermolecular hydrogen bonding interaction between chitosan and $\mathrm{ZnO}$ [32].

The thermogravimetric (TG) curves of chitosan, $\mathrm{ZnO}$ nanoparticles and $\mathrm{ZnO} /$ chitosan nanocomposite were recorded (Figure 4). The TG curve of $\mathrm{ZnO}$ nanoparticles slightly went down as the temperature was increased from 25 to $800^{\circ} \mathrm{C}$. The mass loss of $2.08 \%$ corresponds to the loss of absorbed water (Figure $4(\mathrm{a})$ ). In the TG curve of chitosan, 


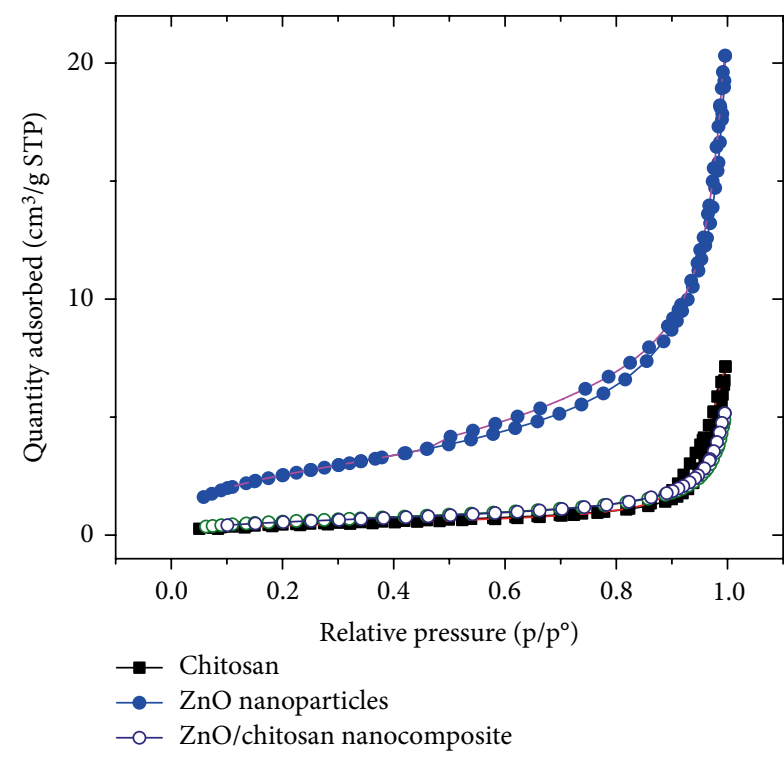

FIGURE 5: Nitrogen adsorption-desorption isotherms of $\mathrm{ZnO}$ nanoparticles, chitosan, and $\mathrm{ZnO} /$ chitosan nanocomposite.

TABle 3: Maximum congo red adsorption capacity of several adsorbents.

\begin{tabular}{lcc}
\hline Adsorbents & $q_{m}(\mathrm{mg} / \mathrm{g})$ & References \\
\hline $\mathrm{Fe}_{3} \mathrm{O}_{4} / \mathrm{Bi}_{2} \mathrm{~S}_{3}$ microspheres & 92.24 & {$[39]$} \\
MWCNTs/calcined eggshell & 136.99 & {$[40]$} \\
Magnetic CS/carrageenan ampholy- & 212.7 & {$[41]$} \\
tic microspheres & & \\
Chitosan coated magnetic $\mathrm{Fe}_{3} \mathrm{O}_{4}$ & $42.62-56.66$ & {$[42]$} \\
particle & 208 & {$[43]$} \\
Zinc peroxide nanomaterial & 304 & {$[44]$} \\
$\mathrm{ZnO}$ microspheres & 125 & {$[45]$} \\
$\mathrm{Mg}$-doped ZnO NPs & 334 & {$[46]$} \\
Hierarchical porous ZnO & 227.3 & This study \\
ZnO/chitosan nanocomposite & &
\end{tabular}

there are three stages of mass loss (Figure 4(b)). The first stage occurs from 50 to $120^{\circ} \mathrm{C}$ and reaches to the maximum degradation rate at $107.2^{\circ} \mathrm{C}$ with $13.49 \%$ mass loss, referring to the dehydration process. The second stage (from 220 to $350^{\circ} \mathrm{C}$ ) with $26.50 \%$ mass loss may be due to the degradation and decomposition of the backbone chain of volatile fraction. The last stage (from 350 to $800^{\circ} \mathrm{C}$ ) with $16.65 \%$ mass loss may relate to the decomposition of the backbone chain of residual chitosan [33]. A noticeable three-stage mass loss was also observed in the TG curve of $\mathrm{ZnO} /$ chitosan nanocomposite (Figure $4(\mathrm{c})$ ). The first stage at the temperature from $50^{\circ} \mathrm{C}$ to $150^{\circ} \mathrm{C}$ is accounted for the thermal dehydration. The last two stages with the approximate total mass loss of $16.21 \%$ (from 220 to $350^{\circ} \mathrm{C}$ ) and $8.67 \%$ (from 350 to $600^{\circ} \mathrm{C}$ ) are presumed to be the thermal decomposition of volatile and residual chitosan in the nanocomposite, respectively. The maximum degradation rate of volatile chitosan is shifted from $251.8^{\circ} \mathrm{C}$ in chitosan to $261.2^{\circ} \mathrm{C}$ in the nanocomposite, while that of residual chitosan is shifted from $440.8^{\circ} \mathrm{C}$ in chitosan to $459.5^{\circ} \mathrm{C}$ in

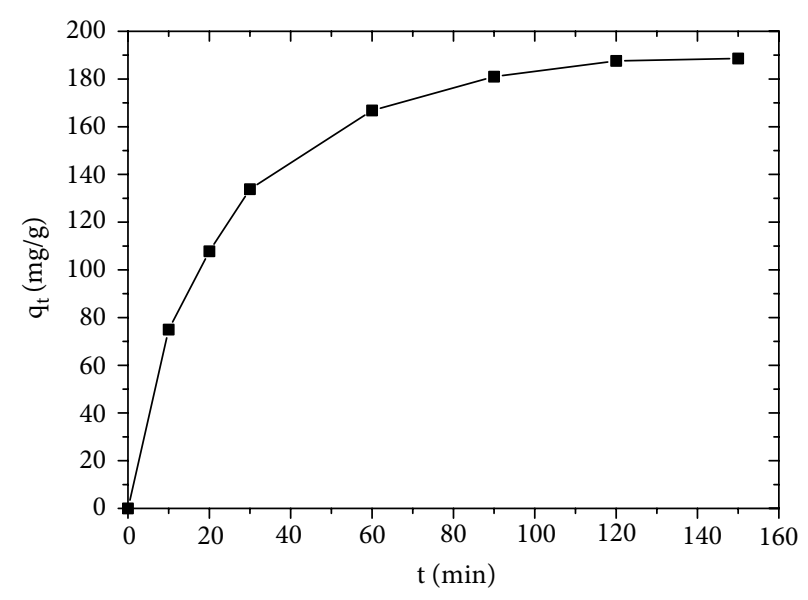

FIgURE 6: The relationship between adsorption capacity of $\mathrm{ZnO} /$ chitosan nanocomposite and adsorption time (volume: $40 \mathrm{~mL}$; adsorbent dose: $0.02 \mathrm{~g}$; initial congo red concentration: $100 \mathrm{mg} / \mathrm{L}$ ).

the nanocomposite. The formation of hydrogen bonding between chitosan and zinc oxide in the composite may be responsible to this phenomenon [21].

Nitrogen adsorption-desorption isotherms of $\mathrm{ZnO}$ nanoparticles, chitosan, and $\mathrm{ZnO} /$ chitosan nanocomposite are displayed in Figure 5. The three materials have type IV isotherm (IUPAC classification) [34]. Moreover, the very narrow hysteresis loops at high (chitosan and nanocomposite) and moderate relative pressure ( $\mathrm{ZnO}$ nanoparticles) indicate the presence of mesopores in their structure [34-36]. The similarity between the isotherms of chitosan, and $\mathrm{ZnO}$ /chitosan nanocomposite shows the similar porous structures of the two materials. BET surface areas of $\mathrm{ZnO}$ nanoparticles, chitosan, and $\mathrm{ZnO} /$ chitosan nanocomposite are 9.7852, 1.7461, and $2.2436\left(\mathrm{~m}^{2} / \mathrm{g}\right)$, respectively (Table 1$)$. The average pore size of the nanocomposite is $12.2 \mathrm{~nm}$.

\subsection{Congo Red Adsorption by ZnO/Chitosan}

Nanocomposite. The relationship between adsorption capacity of $\mathrm{ZnO} /$ chitosan nanocomposite and adsorption time is illustrated in Figure 6 . The adsorption capacity sharply rises within the first 30 minutes and negligibly changes after 120 minutes. Therefore, the reaction time in other adsorption experiments is selected to be 120 minutes.

The two most common adsorption isotherms including the Langmuir and Freundlich adsorption isotherms were applied to characterize the adsorption of congo red by $\mathrm{ZnO} /$ chitosan nanocomposite. The Langmuir model assumes monolayer adsorption of the adsorbate with no interaction among adsorbate molecules, whereas the Freundlich model assumes multilayer adsorption of the adsorbate.

Corresponding mathematical expressions of the Langmuir and Freundlich adsorption isotherms are written as $[37,38]$ :

$$
\begin{gathered}
\frac{C_{e}}{q_{e}}=\frac{C_{e}}{q_{m}}+\frac{1}{q_{m} \cdot K_{L}}, \\
\log q_{e}=\log K_{F}+\frac{1}{n} \log C_{e},
\end{gathered}
$$




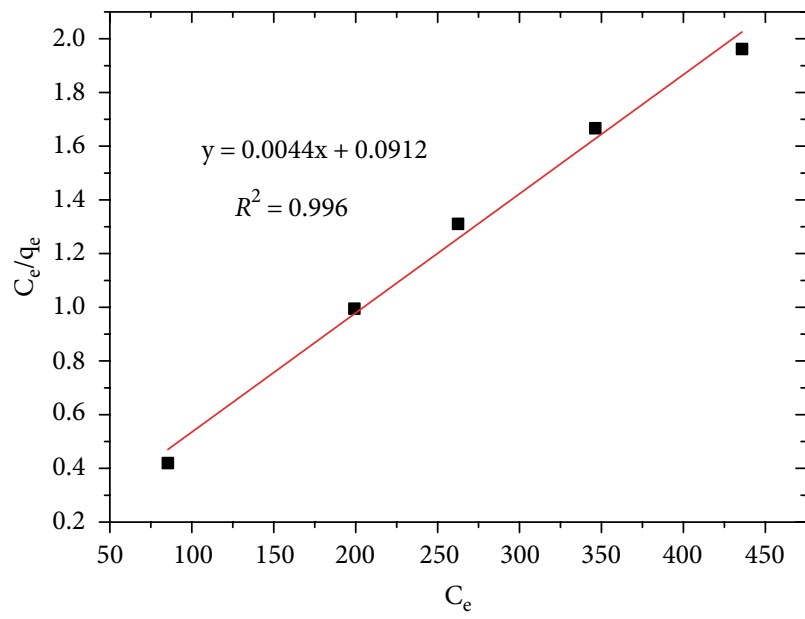

(a)

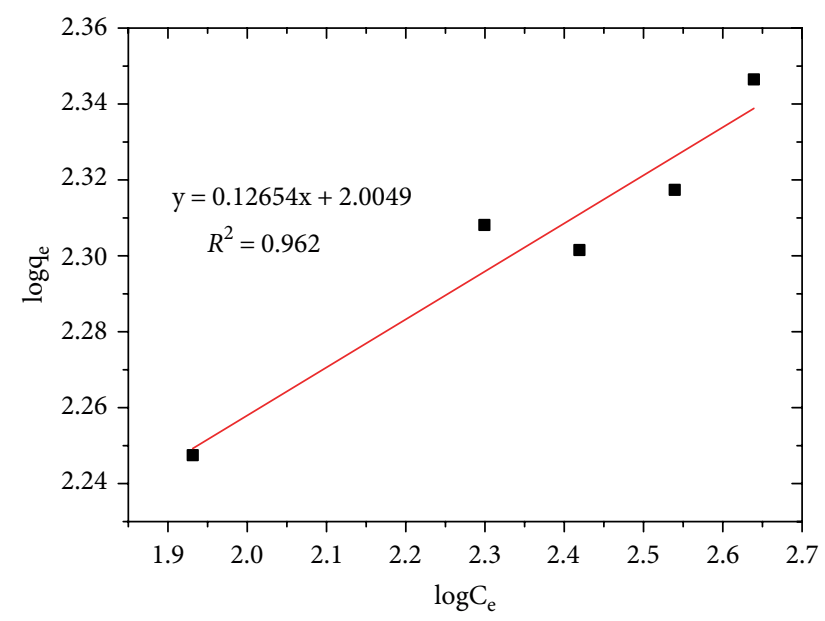

(b)

FIgURE 7: Adsorption isotherm for congo red adsorption by $\mathrm{ZnO} /$ chitosan nanocomposite: (a) Langmuir and (b) Freundlich.

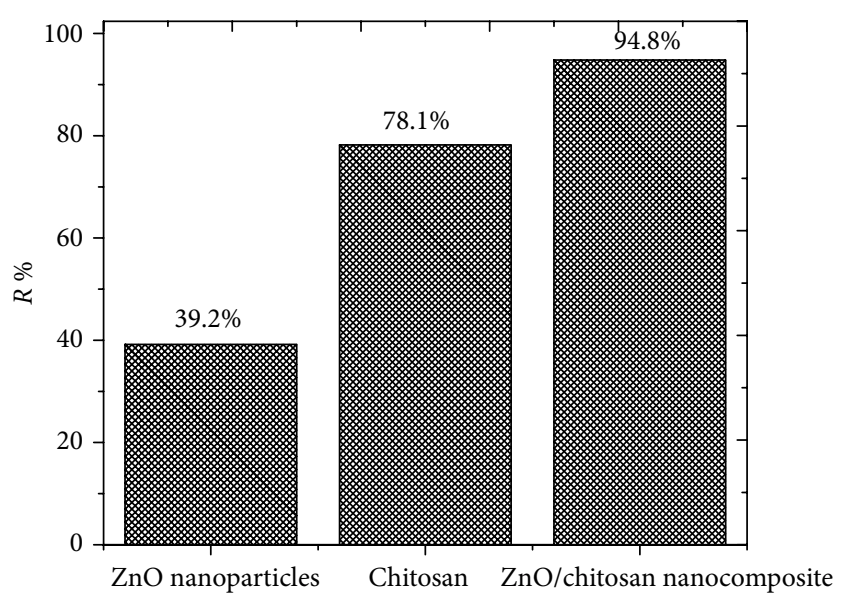

Figure 8: Congo red removal efficiencies of $\mathrm{ZnO}$ nanoparticles, chitosan and $\mathrm{ZnO} /$ chitosan nanocomposite (volume: $40 \mathrm{~mL}$; adsorbent dose: $0.02 \mathrm{~g}$; initial concentrations: $100 \mathrm{mg} \cdot \mathrm{L}^{-1 ;} \mathrm{pH}$ values at equilibrium: about 6.5).

where: $q_{e}(\mathrm{mg} / \mathrm{g})$ is the amount of congo red adsorbed at equilibrium, $q_{m}(\mathrm{mg} / \mathrm{g})$ is the theoretical maximum amount of congo red adsorption, $C_{e}(\mathrm{mg} / \mathrm{L})$ is congo red concentration at equilibrium, and $K_{L}(\mathrm{~L} / \mathrm{mg}), K_{F}\left((\mathrm{mg} / \mathrm{g}) .(\mathrm{L} / \mathrm{mg})^{1 / \mathrm{n}}\right)$ are the Langmuir and Freundlich constants, respectively.

The linear plots of the Langmuir and Freundlich models for congo red adsorption by $\mathrm{ZnO} /$ chitosan nanocomposite are presented in Figure 7. Table 2 summarizes calculated values of Langmuir and Freundlich model's parameters. Obtained results suggest that the congo red adsorption is better described by the Langmuir model with the significant coefficient correlation $R^{2}$ of 0.996 than by the Freundlich model $\left(R^{2}=0.962\right)$. Therefore, it can be presumed that congo red was adsorbed in a single monolayer with the theoretical maximum adsorption capacity of $227.3(\mathrm{mg} / \mathrm{g})$. The maximum adsorption capacity of the synthesized $\mathrm{ZnO} /$ chitosan nanocomposite is comparable with other adsorbents in former studies (Table 3). It can be concluded that the obtained nanocomposite has high potential to be applied for congo red removal.

Comparison among congo red removal efficiencies of $\mathrm{ZnO} /$ chitosan nanocomposite, $\mathrm{ZnO}$ nanoparticles, and chitosan are quite interesting (Figure 8). It is well known that the adsorption capacity strongly depends on the total surface area and the number of binding sites of adsorbents. Despite the fact that the total surface area of $\mathrm{ZnO}$ nanoparticles is approximately 5 times higher than that of chitosan and $\mathrm{ZnO} /$ chitosan nanocomposite, $\mathrm{ZnO}$ nanoparticles have the lowest congo red removal efficiency. More than $90 \%$ of congo red was removed by $\mathrm{ZnO} /$ chitosan nanocomposite after 2 hours and $78.1 \%$ of congo red was eliminated by chitosan, while only $39.2 \%$ of the dye was removed by $\mathrm{ZnO}$ nanoparticles. This suggests that the presence of chitosan in the nanocomposite is mainly responsible for the congo red adsorption capability of the material. In $\mathrm{ZnO} /$ chitosan nanocomposite, the $\mathrm{ZnO}$ may play a role as a rigid support for the thin film of chitosan, which contains $-\mathrm{OH} /-\mathrm{NH}_{2}$ groups. These functional groups probably play a role as binding sites to congo red molecules as proposed in numbers of publications [21, 47]. Further study, however, should be carried out in order to address the exact mechanism of the adsorption process.

\section{Conclusions}

In the present work, the $\mathrm{ZnO} /$ chitosan nanocomposite was successfully generated by direct simple, fast, and eco-friendly in situ precipitation method. XRD results reveal that the nanocomposite has wurtzite structure. The size of the nanocomposite is approximately $20-25 \mathrm{~nm}$. The FESEM and TEM images show the spherical morphology of the material. The similarity in porous structures of chitosan and $\mathrm{ZnO} /$ chitosan nanocomposite was observed. BET surface area of $\mathrm{ZnO} / \mathrm{chi}$ tosan nanocomposite is $2.2436\left(\mathrm{~m}^{2} / \mathrm{g}\right)$ and the average pore size of the nanocomposite is $12.2 \mathrm{~nm}$. The material was applied as an adsorbent in order to remove congo red from aqueous solutions. According to the Langmuir isotherm model, the 
theoretical maximum adsorption capacity of $\mathrm{ZnO} /$ chitosan nanocomposite is 227.3 (mg/g). From this result, it can be suggested that $\mathrm{ZnO} /$ chitosan nanocomposite could serve as a promising adsorbent for congo red in wastewater treatment technology.

\section{Data Availability}

The data used to support the findings of this study are available from the corresponding author upon request.

\section{Conflicts of Interest}

The authors declare that they have no conflicts of interest.

\section{Acknowledgments}

This study was supported by the Ministry of Science and Technology in South Korea through the International Environmental Research Institute (IERI) of Gwangju Institute of Science and Technology (GIST) in 2019.

\section{References}

[1] K. Hunger, Industrial Dyes: Chemistry, Properties, Applications, Wiley-VCH, Weinheim, 2003.

[2] S. K. Sharma, Green Chemistry for Dyes Removal from Wastewater: Research Trends and Applications, Scrivener Publishing, John Wiley \& Sons, USA, 2015.

[3] R. M. Christie, Environmental Aspects of Textile Dyeing, Woodhead Publishing Limited, UK, 2007.

[4] E. Alver, M. Bulut, A. Ü. Metin, and H. Çiftçi, "One step effective removal of Congo Red in chitosan nanoparticles by encapsulation," Spectrochimica Acta Part A: Molecular and Biomolecular Spectroscopy, vol. 171, pp. 132-138, 2017.

[5] X. Liu, J. Tian, Y. Li et al., "Enhanced dyes adsorption from wastewater via $\mathrm{Fe}_{3} \mathrm{O}_{4}$ nanoparticles functionalized activated carbon," Journal of Hazardous Materials, vol. 373, pp. 397-407, 2019.

[6] T.-H. Kim, C. Park, J. Yang, and S. Kim, "Comparison of disperse and reactive dye removals by chemical coagulation and Fenton oxidation," Journal of Hazardous Materials, vol. 112, no. 1-2, pp. 95-103, 2014.

[7] Z. Aslam, M. Qaiser, R. Ali, A. Abbas, Ihsanullah, and S. Zarin, " $\mathrm{Al}_{2} \mathrm{O}_{3} / \mathrm{MnO}_{2} / \mathrm{CNT}$ nanocomposite: synthesis, characterization and phenol adsorption," Fullerenes, Nanotubes and Carbon Nanostructures, vol. 27, no. 7, pp. 591-600, 2019.

[8] A.-N. M. Salem, M. Ahmed, and M. El-Shahat, "Selective adsorption of amaranth dye on $\mathrm{Fe}_{3} \mathrm{O}_{4} / \mathrm{MgO}$ nanoparticles," Journal of Molecular Liquids, vol. 219, pp. 780-788, 2016.

[9] Y. Zhou, L. Jian, Y. Zhou, and Y. Liu, "Recent advances for dyes removal using novel adsorbents: a review," Environmental Pollution, vol. 252, pp. 352-365, 2019.

[10] Q. Lu, J. Zheng, J. Yu et al., "Synthesis and adsorption properties for cationic dyes of acrylic acid/vermiculite hydrogel initiated by glow-discharge-electrolysis plasma," Advances in Polymer Technology, vol. 37, no. 4, 2018.
[11] S. Ghorai, A. K. Sarkar, A. B. Panda, and S. Pal, "Effective removal of Congo red dye from aqueous solution using modified xanthan gum/silica hybrid nanocomposite as adsorbent," Bioresource Technology, vol. 144, pp. 485-491, 2013.

[12] L. Bulgariu, L. B. Escudero, O. S. Bello et al., "The utilization of leaf-based adsorbents for dyes removal: a review," Journal of Molecular Liquids, vol. 276, pp. 728-747, 2019.

[13] A. Zahir, Z. Aslam, M. S. Kamal, W. Ahmad, A. Abbas, and R. A. Shawabkeh, "Development of novel cross-linked chitosan for the removal of anionic Congo red dye," Journal of Molecular Liquids, vol. 244, pp. 211-218, 2017.

[14] I. Tahira, Z. Aslama, A. Abbas, M. Monim-ul-Mehboob, S. Ali, and A. Asghar, "Adsorptive removal of acidic dye onto grafted chitosan: a plausible grafting and adsorption mechanism," International Journal of Biological Macromolecules, vol. 136, pp. 1209-1218, 2019.

[15] M. Vakili, M. Rafatullah, B. Salamatinia et al., "Application of chitosan and its derivatives as adsorbents for dye removal from water and wastewater: a review," Carbohydrate Polymers, vol. 113, pp. 115-130, 2014.

[16] J. M. N. dos Santos, C. R. Pereira, L. A. A. Pinto et al., "Synthesis of a novel $\mathrm{CoFe}_{2} \mathrm{O}_{4} /$ chitosan magnetic composite for fast adsorption of indigotine blue dye," Carbohydrate Polymers, vol. 217, pp. 6-14, 2019.

[17] H. V. Tran, L. T. Bui, T. T. Dinh, D. H. Le, C. D. Huynh, and A. X. Trinh, "Graphene oxide $/ \mathrm{Fe}_{3} \mathrm{O}_{4} /$ chitosan nanocomposite: a recoverable and recyclable adsorbent for organic dyes removal. Application to methylene blue," Materials Research Express, vol. 4, no. 3, p. 035701, 2017.

[18] H. A. Abdel, A. M. Saad, S. T. Azzam, B. B. El-Wakeel, and M. B. Mostafa, "Removal of toxic metal ions from wastewater using ZnO@Chitosan coreshell nanocomposite,"Environmental Nanotechnology, Monitoring \& Management, vol. 9, pp. 67-75, 2018.

[19] P. Bhadra, M. K. Mitra, G. C. Das, R. Dey, and S. Mukherjee, "Interaction of chitosan capped $\mathrm{ZnO}$ nanorods with Escherichia coli," Materials Science and Engineering C, vol. 31, no. 5, pp. 929-937, 2011.

[20] S. Çınar, Ü. H. Kaynar, T. Aydemir, S. Çam Kaynar, and M. Ayvacıklı, "An efficient removal of RB5 from aqueous solution by adsorption onto nano- $\mathrm{ZnO} /$ Chitosan composite beads," International Journal of Biological Macromolecules, vol. 96, pp. 459-465, 2017.

[21] M. Blachnio, T. M. Budnyak, A. Derylo-Marczewska, A. W. Marczewski, and V. A. Tertykh, "Chitosan-silica hybrid composites for removal of sulfonated azo dyes from aqueous solutions," Langmuir, vol. 34, no. 6, pp. 2258-2273, 2018.

[22] Joint Committee for Powder Diffraction Society (JCPDS), "Powder diffraction database, pattern," pp. 1436-1451, 1972.

[23] L.-H. Li, J.-C. Deng, H.-R. Deng, Z.-L. Liu, and L. Xin, "Synthesis and characterization of chitosan/ZnO nanoparticle composite membranes," Carbohydrate Research, vol. 345, no. 8, pp. 994-998, 2010.

[24] K. Raja, P. S. Ramesh, and D. Geetha, "Structural, FTIR and photoluminescence studies of Fe doped $\mathrm{ZnO}$ nanopowder by co-precipitation method," Spectrochimica Acta Part A: Molecular and Biomolecular Spectroscopy, vol. 131, pp. 183-188, 2014.

[25] E. Selvarajan and V. Mohanasrinivasan, "Biosynthesis andcharacterization of $\mathrm{ZnO}$ nanoparticles using Lactobacillus plantarum VITES07," Materials Letters, vol. 112, pp. 180-182, 2013. 
[26] D. Wu, W. Wang, F. Tan, F. Sun, H. Luand, and X. Qiao, "Fabrication of pit-structured $\mathrm{ZnO}$ nanorods and their enhanced photocatalytic performance," RSC Advances, vol. 3, no. 43, pp. 20054-20059, 2013.

[27] H. Wang, X. Gong, Y. Miao et al., "Preparation and characterization of multilayer films composed of chitosan, sodium alginate and carboxymethyl chitosan- $\mathrm{ZnO}$ nanoparticles," Food Chemistry, vol. 283, pp. 397-403, 2019.

[28] Lijun You, Ci Huang, Lu Feifei, Ao Wang, Xiaocui Liu, and Q. Zhang, "Facile synthesis of high performance porous magnetic chitosan-polyethylenimine polymer composite for Congo red removal," International Journal of Biological Macromolecules, vol. 107, pp. 1620-1628, 2018.

[29] M. Hasmath Farzana and S. Meenakshi, "Visible light-driven photoactivity of zinc oxide impregnated chitosanbeads for the detoxification of textile dyes," Applied Catalysis A: General, vol. 503, pp. 124-134, 2015.

[30] Z. Huang, Z. Li, L. Zheng et al., “ Interaction mechanism of uranium (VI) with three-dimensional graphene oxide-chitosan composite: Insights from batch experiments, IR, XPS, and EXAFS spectroscopy," Chemical Engineering Journal, vol. 328, pp. 1066-1074, 2017.

[31] E. Zabihi, A. Babaei, D. Shahrampour, Z. Arab-Bafrani, K. S. Mirshahidi, and H. J. Majidi, "Facile and rapid in-situ synthesis of chitosan- $\mathrm{ZnO}$ nano-hybrids applicable in medical purposes; a novel combination of biomineralization, ultrasound, and bio-safe morphology-conducting agent," International Journal of Biological Macromolecules, vol. 131, pp. 107-116, 2019.

[32] B. Qiu, X.-F. Xu, R.-H. Deng, G.-Q. Xia, X.-F. Shang, and P.-H. Zhou, "Construction of chitosan/ZnO nanocomposite film by in situ precipitation," International Journal of Biological Macromolecules, vol. 122, pp. 82-87, 2019.

[33] F. A. López, A. L. R. Mercê, F. J. Alguacil, and A. López-Delgado, "A kinetic study on the thermal behaviour of chitosan," Journal of Thermal Analysis and Calorimetry, vol. 91, no. 2, pp. 633-639, 2008.

[34] K. S. W. Sing, "Reporting physisorption data for gas/solid systems with special reference to the determination of surface area and porosity," Pure and Applied Chemistry, vol. 54, no. 11, pp. 2201-2218, 1982.

[35] N. Farhadian, R. Akbarzadeh, M. Pirsaheb, T.-C. Jen, Y. Fakhri, and A. Asadi, "Chitosan modified N, S-doped $\mathrm{TiO}_{2}$ and $\mathrm{N}$, $\mathrm{S}$-doped $\mathrm{ZnO}$ for visible light photocatalytic degradation of tetracycline," International Journal of Biological Macromolecules, vol. 132, pp. 360-373, 2019.

[36] Y. Zheng, B. Cheng, W. You, J. Yua, and W. Ho, “3D hierarchical graphene oxide-NiFe LDH composite with enhanced adsorption affinity to Congo red, methyl orange and Cr(VI) ions," Journal of Hazardous Materials, vol. 369, pp. 214-225, 2019.

[37] H. Haojun, J. Liu, X. Zhihua, L. Zhang, B. Cheng, and W. Ho, "Hierarchical porous Ni/Co-LDH hollow dodecahedron with excellent adsorption property for Congo red and $\mathrm{Cr}(\mathrm{VI})$ ions," Applied Surface Science, vol. 478, pp. 981-990, 2019.

[38] Y. Zheng, J. Liu, B. Cheng, W. You, W. Hoc, and H. Tang, "Hierarchical porous $\mathrm{Al}_{2} \mathrm{O}_{3} @ \mathrm{ZnO}$ core-shell microfibres with excellent adsorption affinity for Congo red molecule," Applied Surface Science, vol. 473, pp. 251-260, 2019.

[39] R. Huayue Zhu, J. L. Jiang, F. Yongqian, S. Jiang, and J. Yao, "Magnetically recyclable $\mathrm{Fe}_{3} \mathrm{O}_{4} / \mathrm{Bi}_{2} \mathrm{~S}_{3}$ microspheres for effective removal of Congo red dye by simultaneous adsorption and photocatalyticregeneration," Separation and Purification Technology, vol. 179, pp. 184-193, 2017.

[40] E. N. Seyahmazegi, R. Mohammad-Rezaei, and H. Razmi, "Multiwall carbon nanotubes decorated on calcined eggshell waste as a novel nano-sorbent: application for anionic dye Congo red removal," Chemical Engineering Research and Design, vol. 109, pp. 824-834, 2016.

[41] X. Liang, J. Duan, Q. Xua, X. Wei, A. Lu, and L. Zhang, "Ampholytic microspheres constructed from chitosan and carrageenan in alkali/urea aqueous solution for purification of various wastewater," Chemical Engineering Journal, vol. 317, pp. 766-776, 2017.

[42] H. Zhu, M. Zhang, Y. Liu, L. Zhang, and R. Han, "Study of Congo red adsorption onto chitosan coated magnetic iron oxide in batch mode," Desalination and Water Treatment, vol. 37, pp. 46-54, 2012.

[43] S. Chawla, H. Uppal, M. Yadav, N. Bahadur, and N. Singh, "Zinc peroxide nanomaterial as an adsorbent for removal of Congo red dye from wastewater," Ecotoxicology and Environmental Safety, vol. 135, pp. 68-74, 2017.

[44] C. Lei, M. Pi, B. Chenga, C. Jiang, and J. Qin, "Fabrication of hierarchical porous $\mathrm{ZnO} / \mathrm{NiO}$ hollow microspheres for adsorptive removal of Congo red," Applied Surface Science, vol. 435, pp. 1002-1010, 2018.

[45] P. P. Ratha, S. S. Beheraa, B. Priyadarshini et al., "Influence of Mg doping on ZnO NPs for enhanced adsorption activity of Congo Red dye," Applied Surface Science, vol. 491, pp. 256-266, 2019.

[46] C. Lei, M. Pi, C. Jiang, B. Cheng, and J. Yu, "Synthesis of hierarchical porous zinc oxide $(\mathrm{ZnO})$ microspheres with highly efficient adsorption of Congo red," Journal of Colloid and Interface Science, vol. 490, pp. 242-251, 2017.

[47] A. Mokhtar, S. Abdelkrim, A. Djelad et al., "Adsorption behavior of cationic and anionic dyes on magadiite-chitosan composite beads," Carbohydrate Polymers, vol. 229, p. 115399, 2020. 


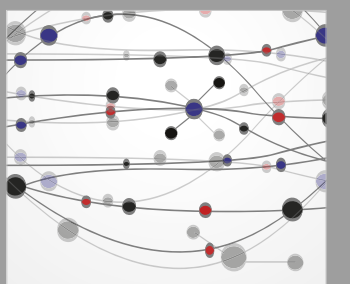

The Scientific World Journal
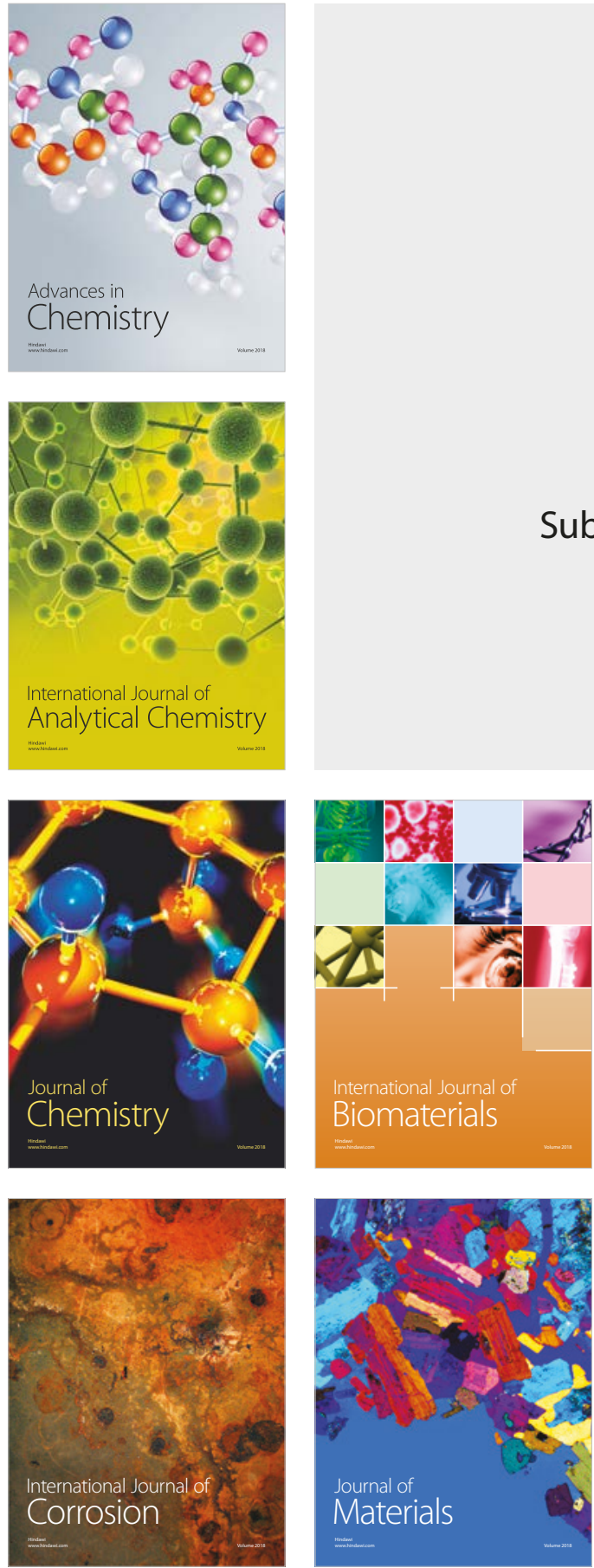

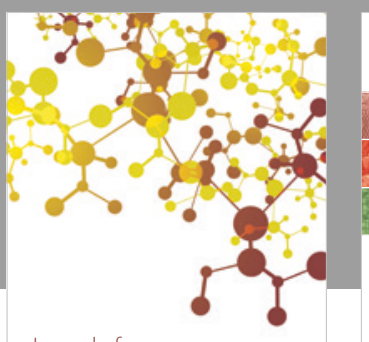

Journal of

Applied Chemistry
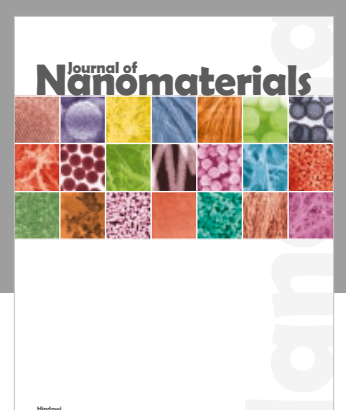

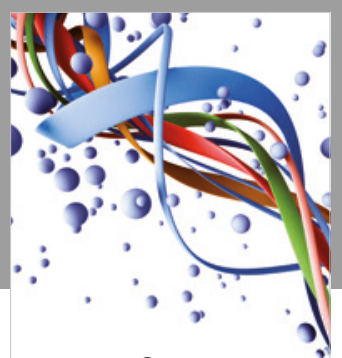

Scientifica

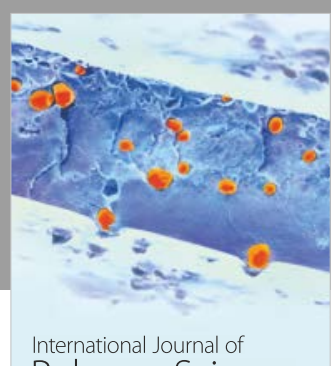

Polymer Science

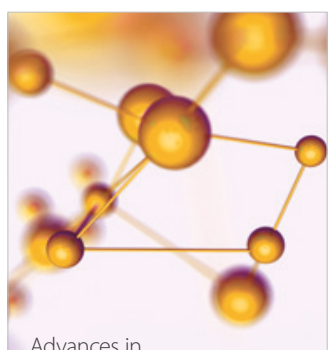

Physical Chemistry
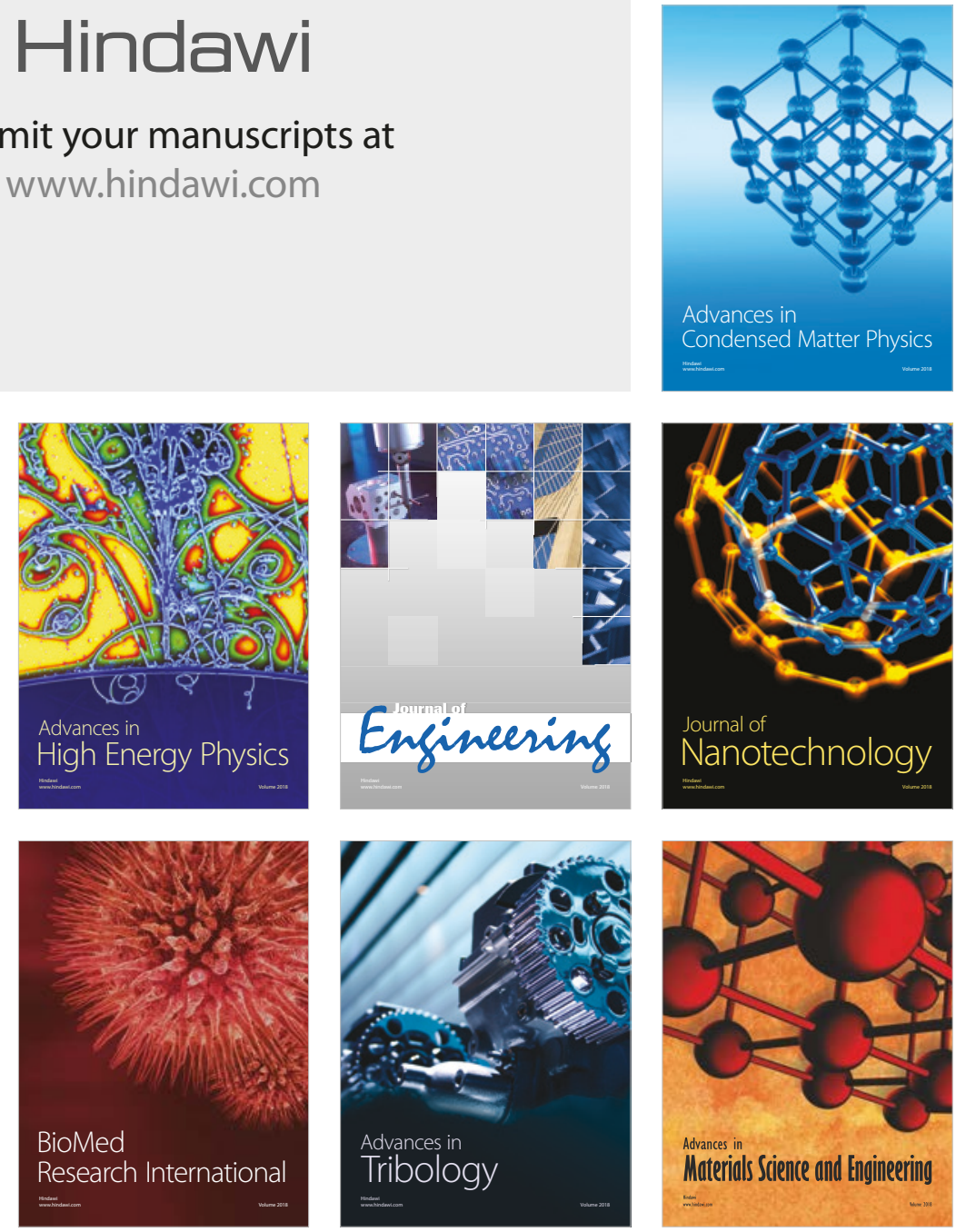